\title{
On Better Engineering Preparedness: Lessons from the 1988 Bihar Earthquake
}

\author{
Earthquake Spectra, EERI, Vol.8, No.3, 1992
}

Sudhir K. Jain

Department of Civil Engineering

Indian Institute of Technology Kanpur

\begin{abstract}
The rather moderate sized (magnitude 6.6) Bihar earthquake of August 21, 1988 demonstrated clearly that the Indian Engineering profession is far from prepared for a larger earthquake. During the author's extensive travel within the areas affected by this earthquake, it became clearer that the engineering community should immediately initiate serious and coordinated efforts to prepare for the possibility of a large earthquake in many parts of India or nearby countries. This paper discusses some such efforts and possible strategies. Suggested strategies for being better prepared include rationalization and implementation of seismic codes, review of actual construction practices, seismic safety evaluation of critical facilities such as dams and refineries, training and preparation of field engineers for handling post-earthquake situations and learning from earthquakes.
\end{abstract}

\section{Introduction}

An earthquake of magnitude 6.6 occurred close to the India - Nepal border on August 21, 1998 at 4:39:11 hours (Indian Standard Time). The epicenter was located in eastern Nepal between Udaipur and Dharan $\left(26.7^{\circ} \mathrm{N}, 86.8^{\circ} \mathrm{E}\right)$. The focal depth was estimated to be about 36 miles. Widespread devastation and loss of life was reported.

One thousand and four people died (282 in India and 722 in Nepal) and more than 16000 were injured. The affected area consists of mainly the Gangetic alluvial plain of Bihar (India) and Nepal, and the hilly regions of eastern Himalayan ranges. Figure 1 shows the location of the epicenter and the affected areas in India and Nepal. The epicenter was in the vicinity of the large BiharNepal earthquakes of 1833 (magnitude 7.0-7.5) and 1934 (magnitude 8.4). Major damage was observed in 3 distinct areas: the area near the epicenter and the areas around Munger (India) and Bharakpur (near Kathmandu in Nepal). Similar damage was observed in the 1934 earthquake and is due to the peculiar geology of the area (e.g., Richter, 1958; GSI, 1939). 
During the earthquake, ground fissuring and emission of sandy water were observed at many places in the Darbhanga and Madhubani districts of Bihar, while no signs of liquefaction were seen at Munger. There was significant damage to embankments, railway bridges and buildings in Bihar. In addition, hilly regions of Darjeeling district (in the state of West Bengal) and Sikkim, located far away (approximately 125 miles) from the epicenter, sustained extensive damage, including damage in roads and highway bridges.

Despite the tragic loss of life and property caused by the earthquake, it provided an opportunity to learn how to be better prepared for larger earthquakes and how to mitigate the damaging effects of future earthquakes. Through this earthquake, nature conducted a real-life full-scale test on construction practices in India as well as on our post-earthquake performance and ability to respond to earthquakes. During the author's extensive travel in north Bihar, Sikkim, and Darjeeling, many instances were noted where the engineering community could have been much better prepared, and consequently, could have responded much more effectively and efficiently. In this paper, these and other related areas in which we must initiate coordinated efforts to prepare ourselves are discussed.

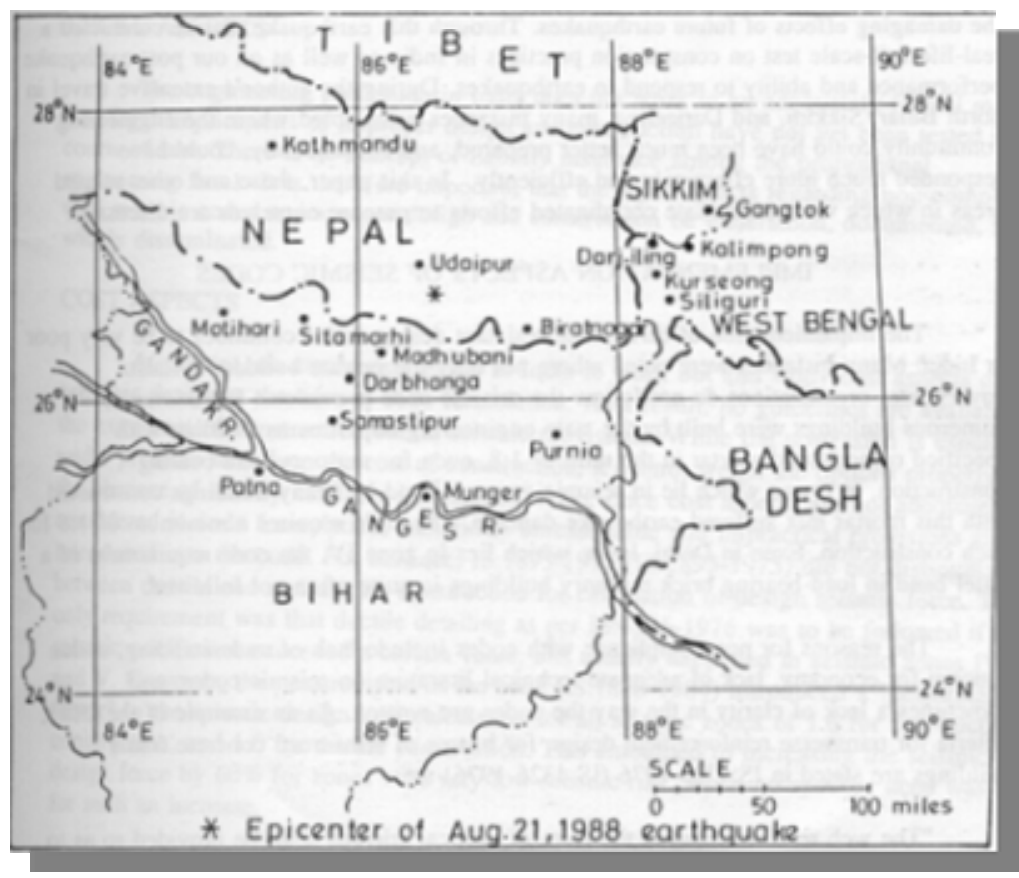

Figure 1: Affected areas of the earthquake 


\section{Implementation Effects of Seismic Codes}

The implementation of earthquake resistant design codes continues to be very poor in India. Many instances were noted where not only the private builders but also government organizations do not follow the seismic code provisions. For example, numerous buildings were built by the state engineering departments in Bihar with specified cement/sand mortar in the ratio of 1:8, even for masonry load bearing construction, in towns, which lie in seismic zones IV and V. Many buildings constructed with this mortar mix suffered earthquake damage. The code requires a minimum of 1:6 for such construction. Even in Delhi, India, which lies in zone IV, the code requirement of a lintel band in load-bearing brick masonry buildings is quite often not allowed.

The reasons for non-compliance with codes include lack of understanding, undue concern for economy, lack of adequate technical literature on seismic codes, and sometimes lack of clarity in the way the codes are written. As an example of the latter, criteria for traverse reinforcement design for beams of reinforced concrete frame buildings are stated in IS: 4326-1976 (IS: 4326-1976) as:

"The web reinforcement in the form of vertical stirrups shall be provided so as to develop the vertical shears resulting from all ultimate vertical loads acting on the beam plus those which can be produced by the plastic moment capacities at the ends of the beam. The spacing of the stirrups shall not exceed $d / 4$ in a length equal to $2 d$ near each end of the beam and $d / 2$ in the remaining length."

It is seen that very few design engineers in India understand the intent and spirit of this clause, particularly the first statement which aims at preventing the brittle shear failure preceding the ductile flexural failure. Moreover, the code does not define "plastic moment capacity". More often than not, design engineers follow the second statement on spacing of shear reinforcement and ignore the first statement.

Obviously, the codes cannot be reinforced unless the difficulties faced by the design and engineering profession in implementation are removed and the codes are rendered comprehensible. Thus, there is a need to understand, rationalize and implement code provisions on seismic design. To accomplish this, it is suggested that a committee be established on which are actively represented government engineering departments, consulting engineers, builders and contractors, legal experts, the Bureau of Indian standards, and researchers in earthquake resistant design. Once established, this committee must look into the following aspects: 


\section{Legal Aspects}

The engineering profession in India does not work in an adequately formal manner. The legal implications of improper design and construction have not yet been tested in the courts of law. There is no concept of liability insurance among the professional engineering firms. It is therefore important that the legal aspects regarding non-compliance with seismic codes or improper design and construction be understood, documented and widely disseminated.

\section{Cost Aspects}

At present, no mechanism exists in India to work out and study cost aspects of Aseismic design at the time of code formulation. As a result, no guidelines are available on the extra cost of construction due to seismic provisions. While the profession is usually under pressure to reduce the cost of construction, it cannot weigh the options properly in the absence of readily available information. Also, since cost aspects are not adequately considered in code formulation, sometimes unreasonable and impractical provisions are introduced into the code. For instance, IS:1893-1975 (IS:1893-1975) did not distinguish between ductile and non-ductile construction for calculation of design seismic force. The only requirement was that ductile detailing as per IS:4326-1976 was to be followed if the seismic coefficient exceeded a certain value; this usually happened in seismic zones IV and V. However, the next revision of the code (IS:1893-1984) introduced a "performance factor" in the seismic design load calculation for all seismic zones of 1.6 for non ductile construction, and 1.0 for ductile construction. This amounted to increasing the seismic design force by $60 \%$ for zones with very low seismic risk, when no specific need was felt for such an increase.

Thus, proper studies on the cost aspects of code provisions are essential for implementations as well as rationalization of codes. Such studies will also help in evolving better engineering solutions for earthquake protection to buildings. It may turn out that the increase in cost of construction to make buildings earthquake resistant, when compared to the overall cost of building, is significant provided the proper choice of structural system has been made. Such a conclusion on the basis of detailed scientific studies will encourage Aseismic construction. The committee would draw benefit from similar studies done elsewhere, for instance, by the committee set up by the structural Engineers Association of California (SEAOC, 1970). Table 1 summarizes the estimated increase in cost to provide earthquake resistant design and construction in the USA as developed by SEAOC. A study on cost implications of the code provisions in India has been conducted recently (Jain and Patnaik, 1991) on three 
real life reinforced concrete frame buildings. Many more such detailed studies of buildings with a greater number of stories, varying configuration and design features and shear walls, as well of masonry and non-engineered structures need to be undertaken.

The existing procedures in India for formulation of design codes, in particular, the seismic codes, need to be modified so that mechanisms become available to adequately consider the cost aspects at the time of Codal revisions.

\section{Propagation Aspects}

The committee must also evaluate whether the letter and spirit of code provisions on seismic design and detailing can be understood by engineers who have not been specifically trained in this art. If not, the committee must suggest:

1. Improvements in codes to make them more clear and specific;

2. A detailed blueprint on imparting such knowledge to engineers and overseers, as well as local artisans; and

3. Detailed outlines of monographs, handbooks and commentaries that must be prepared to bring earthquake resistant design within a common engineer's/supervisor's comprehension.

\section{Review of Actual Construction Practices in the Country}

India is a large country and its communication network is not yet fully developed; therefore a very wide variation exists in actual construction practices in different parts of the country. In some seismic areas there is not much concern for seismic safety, while in other areas private builders are quite aware of the potential earthquake hazard even if not properly trained in Aseismic construction. For instance, in Bihar during the recent earthquake long stretches of flood control embankments subsided by a very significant amount (Jain, Tripathi and Agrawal, 1991). Total absence of compaction in construction of these embankments was largely responsible for this. Figure 2 shows the repair of one such subsided embankment with obviously no compaction even after the earthquake. On the other hand, the author found much better awareness in Siliguri (in the state of West Bengal) of earthquake resistant design among government as well as private builders. This went to the extent that even in the reinforced concrete frame buildings a lintel band is commonly provided in private construction (Figure 3); except that it does not act as a band because it is not continuous through the columns and around the building. Obviously in the latter case a very encouraging climate exists for earthquake resistant construction 
but the builders lack proper training and hence misunderstand the code provision of lintel band in masonry load bearing construction as noted by it being applied to filler walls in frame buildings.

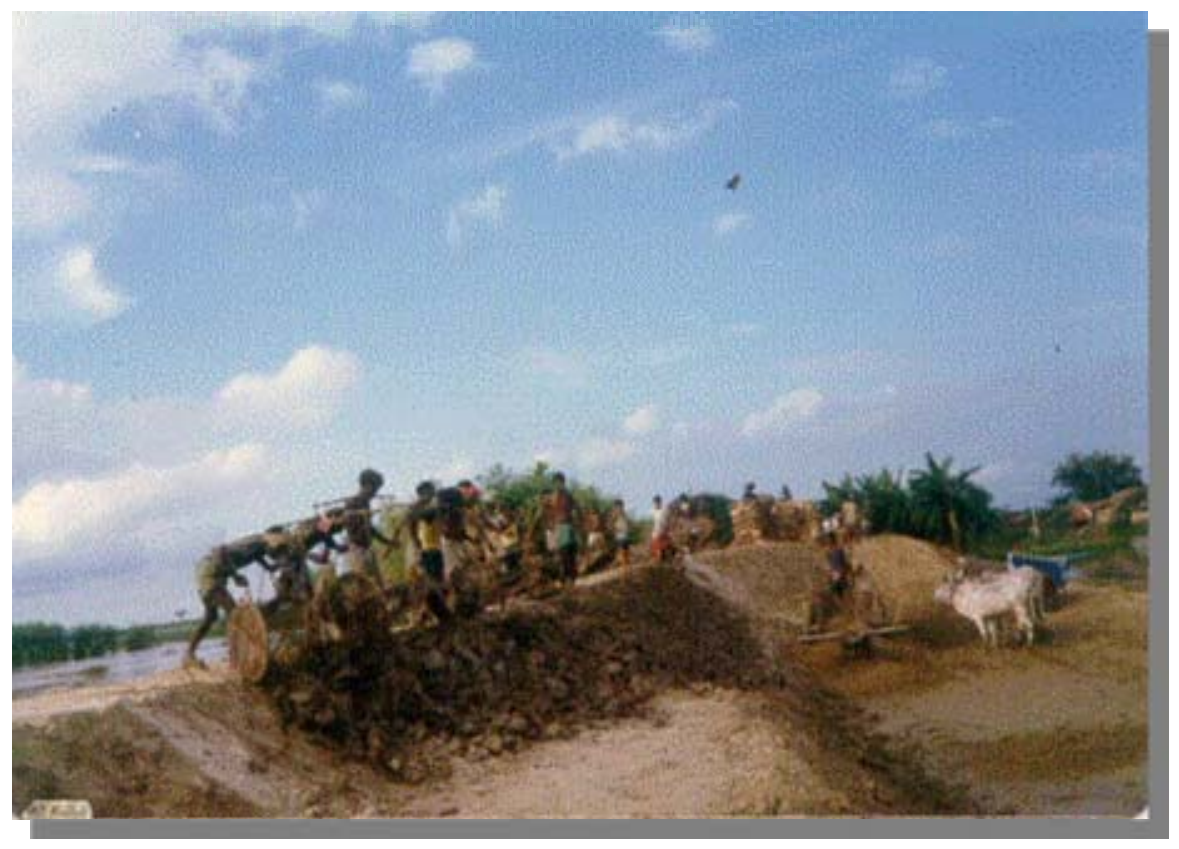

Figure 2: Restoration of a subsided embankment without any compaction

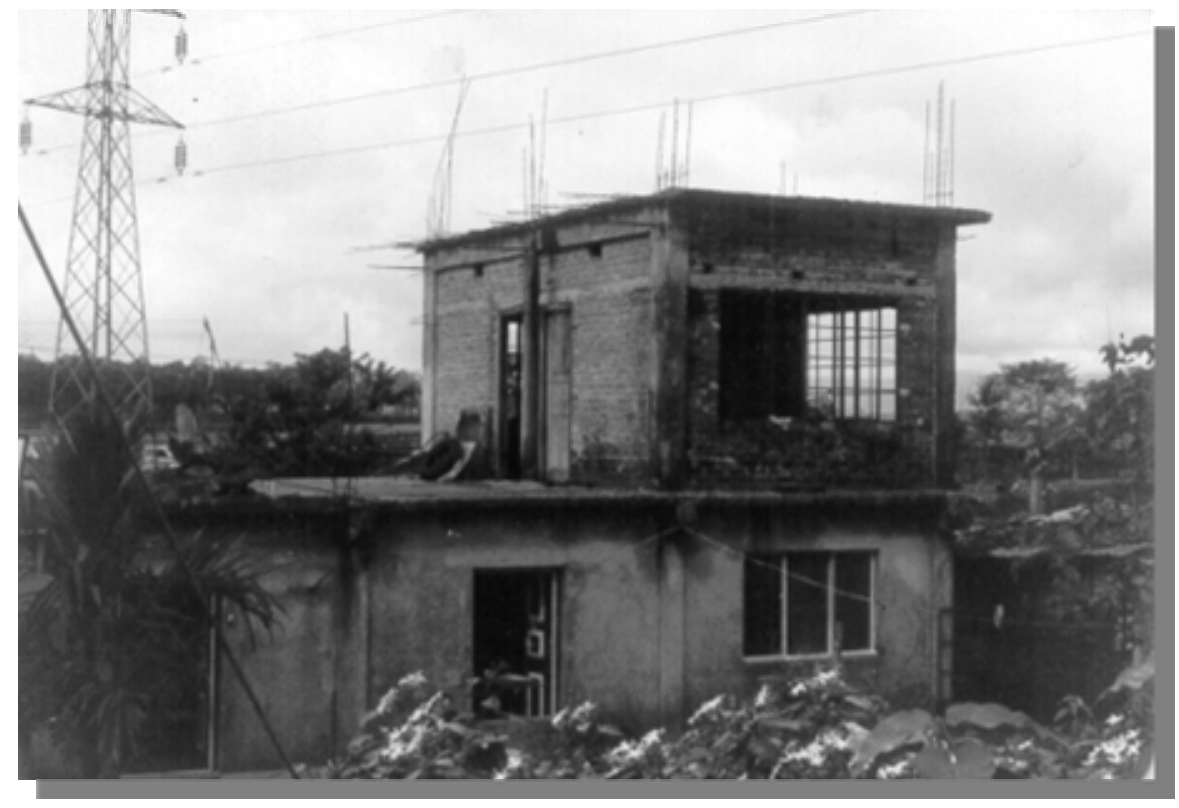

Figure 3: R.C. Frame Building in Siliguri with 'Lintel Band' 
Table1: Estimated increased cost to provide Earthquake Resistance in structures in USA. [Adapted from Degenkolb et al, 1970]

\begin{tabular}{|l|c|c|c|}
\hline \multirow{1}{*}{ Type of Building } & \multicolumn{3}{|c|}{ Increase in Cost (\%) } \\
\cline { 2 - 4 } & $\begin{array}{l}\text { Areas which } \\
\text { now enforce } \\
\text { design for } \\
\text { hurricane, } \\
\text { cyclone, tornado } \\
\text { or abnormally } \\
\text { high winds }\end{array}$ & $\begin{array}{l}\text { Other US } \\
\text { areas to meet } \\
\text { Zone 3 } \\
\text { requirements }\end{array}$ & $\begin{array}{l}\text { Other US areas } \\
\text { located in Zones 0, 1 } \\
\text { and 2 to provide } \\
\text { minimum } \\
\text { requirements }\end{array}$ \\
\hline 1 \& 2 storey frame & 0.5 & 2.0 & 1.0 \\
\hline $\begin{array}{l}1,2,3 \text { storey in brick or } \\
\text { concrete blocks }\end{array}$ & 4.0 & 8.0 & 4.0 \\
\hline $\begin{array}{l}\text { 4 storey and up in } \\
\text { brick or concrete blocks }\end{array}$ & 5.0 & 10.0 & 5.0 \\
\hline Concrete frame & 2.0 & 5.0 & 2.0 \\
\hline Steel frame & 0.5 & 3.0 & 1.0 \\
\hline
\end{tabular}

Note:

1. Tabulated costs include extra design and inspection costs required in earthquake prone areas since more analysis, drafting and field inspections are customarily required in these areas.

2. The increased cost in percentage is to be pulled up to the complete engineering and architectural building, including structure, foundation walls, architectural treatment, mechanical and electrical facilities. It does not apply to site work such as streets, side walks, paving, and drainage.

Thus, before the implementation of seismic codes can be ensured, a document needs to be prepared on actual construction practices being followed particularly in the seismically active parts of the country. This will give a clear picture of reasons why and where Aseismic design practices are not being followed so that effort can be directed towards specific training and persuasion in such areas.

\section{Seismic Safety Evaluation of Dams and other Critical Facilities}

Numerous dams have been built in the country at different points of time as per the state of engineering knowledge available in the country at that time. Failure of a dam during an earthquake can be very disastrous for the downstream population. In recent years seismic analysis of dams has made significant progress. Now is the time to undertake a program for seismic safety 
evaluation of existing dams with the latest state of the art. This will enable the concerned agencies to retrofit the deficient ones. It must be mentioned here that in such an exercise the safety criteria plays a very significant role and this must be taken into consideration before such an exercise is undertaken. Analysis of the safety of major dams in India is usually performed by the Central Water Commission. However, it seems that in recent years, no comprehensive studies on seismic design assessment of existing dams have been undertaken. One of the possible deterrents to undertaking seismic safety analysis of major dams is the undue politicization of new dam projects and the controversies raised regarding seismic design of future projects.

Similarly, many critical facilities, such as refineries and other chemical factories exist in seismically active zones of the country. The Bhopal disaster has clearly shown the danger they pose to population around them in case of leakage and dissipation of toxic gases. This could indeed take place in case of a moderate to large earthquake. In fact, the recent Bihar earthquake did cause some relatively minor damage to a few facilities of the Indian Oil Corporation refinery at Barauni (Hulyalker, 1988). Hence, all such facilities must be evaluated from an earthquake point of view and necessary strengthening measures should be undertaken.

\section{Handbook on Post Earthquake Evaluation of Buildings}

After the Bihar earthquake, the local engineers found themselves handicapped in handling an altogether different type of technical task created by the earthquake. An earthquake-damaged building poses questions such as:

1. Is the building safe for re-entry by occupants, particularly in view of the likely aftershocks?

2. If the building is unsafe, can some temporary strengthening measures be taken to avoid immediate evacuation in large numbers? The problem becomes particularly difficult in India in view of the large number of government officials living in government owned houses. One would not like to have a substantial number of government officials leave the town, as they are also required for post-earthquake relief work. After the Bihar earthquake, railway engineers faced difficulty because in the absence of alternative accommodation the railway employees were reluctant to vacate the premises even after those buildings were declared unsafe by the concerned engineers.

3. In the long run, is the structure reparable or should it be replaced by a new structure? 
4. If the building is indeed repairable, how and what type of restoration is needed so as to bring it up to the standard of a newly constructed building which complies with the latest seismic code provisions?

All these are quite specialized issues and the average engineer does not confront such a situation often. Hence, a handbook needs to be developed on the evaluation of such buildings with explicit details and case histories. In recent years, the Federal Emergency Management Agency (FEMA) has published a number of similar reports and benefit could be derived from those. After every disastrous earthquake in India, the engineers involved in evaluating such buildings could be encouraged to document their experiences and the handbook could be revised after such major events. This will ensure that the experience gained in a major earthquake is not lost to the engineers who will face such a situation in the future.

\section{Contingency Plans}

Besides the different kinds of technical problems, an earthquake also poses a variety of administrative difficulties and dilemma for engineers and administrators. For instance, what is the role of local government engineers, particularly if the concerned town has only relatively junior engineers, regarding a religious building, which is at the verge of collapse? In Darbhanga, one Mehrab of the local Jama Masjid was severely damaged and its top was in danger of falling and damaging nearby homes. The local residents were obviously concerned and wanted an immediate action by the government. Eventually after a few weeks, the task was undertaken by army engineers. Another issue that is faced by government engineers is damage evaluation of private houses from the point of view of providing financial relief to the residents of restoration. The engineers in the area get very much involved in evaluating government buildings but it is often not clear regarding their role vis-à-vis private houses. This causes significant delays and the agony of the already suffering is increased significantly. In Bihar, it was noted that many residents did not undertake repair and strengthening on their homes for quite some time due to the fear that this might weaken their case for receiving financial aid from the government.

Thus, detailed contingency plans of action, with a clear outline of responsibilities, need to be prepared and widely disseminated for important engineering departments such as the Public Works Department, Water Supply and Sewerage, Electricity, Telephone, Railways, etc. to handle post-earthquake situations without any loss of time in the event of a railway accident wherein each one of its employees knows what he or she is supposed to do. This kind of experience, even if gained from different disasters or natural hazards, will be 
useful in preparing contingency plans for responding to an earthquake. There are separate channels and hierarchies of decision-making in different government departments. However, in an emergency, these departments must coordinate and work together, and thus there is a need to have a separate hierarchy that links and organizes these departments for the duration of the emergency. Contingency plans to be developed should address these types of issues. A plan of action for the overall district machinery, including engineering departments, was prepared after the Bihar earthquake (Siddiqui, 1988). However, such a plan needs to be more widely circulated for initiating a discussion on it.

\section{Coordination among Engineering Departments}

In recent years, there has been a proliferation of government engineering departments within the states, including many public sector construction corporations. This has led to difficulties in post-disaster management. For instance, many such corporations do not have an adequate infrastructure for maintenance and repairs and are unable to provide immediate relief. The local public works department, even if it has the necessary infrastructure, finds itself unable to help in the matter, for it may amount to interference to a few residential quarters of an educational institution which required only minor repairs to avoid collapse. Therefore, it is very important to devise ways and means for coordination among the numerous engineering departments by sharing resources and expertise in case of an earthquake emergency. For instance, in case of the inability by one of department to handle a situation, the local administration should have the authority to entrust the job to another department, which may be better equipped to handle that situation.

\section{Learning from Future Earthquakes}

Every disastrous earthquake yields valuable experience on performance of manmade structures as well as on post-earthquake solutions. It is well acknowledged that earthquake engineering has progressed more from experience gained from actual earthquake than from laboratory tests. Hence, every effort must be made to properly investigate and document the destructive earthquake. In India, a number of agencies are involved in post-earthquake investigations, for instance, the Indian meteorological department maintains seismograph situations and assigns magnitude to earthquakes, the Geological Survey of India carries out intensive field survey and prepares intensity maps, the Survey of India carries out geodetic surveys in the affected areas after major events, the University of Roorkee maintains the network for string motion Accelerographs under grants from the Department of Science and Technology 
(DST), etc. Depending on which is at the helm of affairs in such agencies, the response varies from earthquake to earthquake. Thus, it usually takes an unusually large amount of time before findings of such agencies become available. Such activities need to be coordinated appropriately to ensure:

1. Quick debriefing of findings by the concerned agencies;

2. Reconciliation of information gathered by more than one agency; and

3. Authentic documentation of the information gathered; the systematic documentation carried out in the US after the Alaska earthquake of 1964 could serve as a model for this.

It is further suggested that a formal project be undertaken in India in line with the learning from earthquake project of the Earthquake Engineering Research Institute (EERI) in the United States. Activities of the EERI project include (EERI, 1991):

1. Conducting post-earthquake field investigation;

2. Developing guidelines for the conduct of field investigations that enable consistency data to be collected; and

3. Disseminating the lessons that are learned from these activities to the professions so that they become incorporated into standards and practice.

A similar project in India could be developed by the DST, which will ensure that we do not miss useful information provided by major earthquakes occurring in and around India.

\section{Conclusion}

India faces devastating floods rather frequently. Thus, while many engineers and administrators are experienced in the handling of a flood disaster, earthquake disasters pose different type of problems. Moreover, natural disaster relief in India is handled by the Ministry of Agriculture and its emphasis remains on floods and droughts. For disasters such as major earthquakes, the Ministry's role gets limited to distribution of relief money to the affected states rather than on a comprehensive plan of relief. These facts make it even more necessary to coordinate systematic efforts in the direction of earthquake preparedness.

Many of the tasks outlined in this paper will require cooperation and coordination of several agencies and departments. While the DST could be the right agency to fund and coordinate such efforts, professional bodies such as the Institution of Engineers (India), Indian concrete Institute and the Indian Society 
of Earthquake Technology could be entrusted with specific tasks, which they can perform through their members.

\section{Acknowledgement}

The author is grateful to the reviewers who made valuable suggestions which enormously helped in improving this paper.

\section{References}

Richter,C.F., (1958), Elementary Seismology, W. H. Freeman \& Co. Inc., San Francisco.

Officers of the Geological Survey of India, and Roy,S.C., (1939), "The BiharNepal Earthquake of 1934," Memoirs of the Geological Survey of India, Vol.73.

IS:4326-1976, Indian Standard Code of Practice for Earthquake Resistant Design and Construction of Buildings (First Revision), Bureau of Indian Standards, New Delhi.

IS:1893-1975, Indian Standard Criteria for Earthquake Resistant Design of Structures (Third Revision), Bureau of Indian Standards, New Delhi.

IS:1893-1984, Indian Standard Criteria for Earthquake Resistant Design of Structures (Fourth Revision), Bureau of Indian Standards, New Delhi.

Degenkolb, H.J. (Chairman), Gizienski,S.F., Meehan,J.F., Massinger,D.L., and Pinkham,C.W., (1970), "Report of the ad-hoc committee on Cost of Design for Earthquakes, Appendix B," Proceedings of the Structural Engineers Association of California, SEAOC, 171 Second Street, San Francisco, California 94105.

Jain,S.K., and Patnaik,A.K., (1991), "Design and Cost Implications of I.S. Code Provisions for Aseismic Design of RC Frame Buildings" Bulletin of the Indian Society of Earthquake Technology, Vol.28, No.2, pp 17-31.

Jain,S.K., Tripathi,R.P., and Agrawal,A.K., (1991), "Geotechnical Damage due to Bihar Earthquake of 1988," Proceedings of Second International Conference on Recent Advances on Geotechnical Engineering and Soil Dynamics, pp 519-524. St. Louis, Missouri.

Hulyalkar,N.K., (1988), "Effect of Earthquake on Barauni Refinery on 21 st August, 1988," Workshop on Bihar-Nepal Earthquake of August 21, 1988, Indian Institute of Technology, Kanpur, 28-29 December 1988.

Siddiqui, I., (1988), "Post-Event Handling of Earthquake Disasters" Workshop on Bihar-Nepal Earthquake of August 21, 1988, Indian Institute of Technology, Kanpur, 28-29 December 1988.

EERI, (1991), Learning from Earthquakes Project: Earthquake Response Plan and Field Guide, Earthquake Engineering Research Institute, Oakland, California. 